\title{
The Ex Vivo Human Placental Transfer of the Anti-HIV Nucleoside Inhibitor Abacavir and the Protease Inhibitor Amprenavir
}

\author{
R.E. Bawdon \\ Department of Obstetrics and Gynecology, The University of Texas Southwestern Medical Center at \\ Dallas, $T X$
}

\begin{abstract}
Objective: The transfer of abacavir, a new nucleoside inhibitor, and amprenavir, a new protease inhibitor, used for the treatment of human immunodeficiency virus, has been studied in the $e x$ vivo human placental model.

Methods: The ex vivo human placental model used $\mathrm{C}^{14}$ antipyrine to determine the transport fraction and clearance index of these compounds at both the peak and trough serum concentrations. The clearance index accumulation and tissue concentrations were determined for each drug by high pressure liquid chromatography.

Results: The clearance index of abacavir was $0.47 \pm 0.19$ and $0.50 \pm 0.07$ at peak and trough concentrations, respectively. The clearance index of amprenavir was $0.38 \pm 0.09$ and $0.14 \pm 0.08$ at peak and trough concentrations, respectively. There was no unusual accumulation of either drug in the media or tissue when the perfusion system was closed.

Conclusion: Abacavir is the first nucleoside compound studied in the perfusion system with a high clearance index. The transfer of the protease inhibitor amprenavir had a clearance index 2.75 times greater than the clearance index of ritonavir at peak concentration determined in a previous study. At trough concentration the clearance index was much less than at the peak concentration. A similar result was found with ritonavir. Infect. Dis. Obstet. Gynecol. 6:244-246, 1998. (C) 1999 Wiley-Liss, Inc.
\end{abstract}

KEY WORDS

ex vivo human placenta perfusion; nucleoside inhibitor; protease inhibitor

$\mathrm{T}$ he number of pregnant women with human immunodeficiency virus (HIV) worldwide continues to increase. Human immunodeficiency virus mutates to become drug resistant very readily in response to treatment with either single or dual anti-HIV therapy, so aggressive therapy using three or more anti-HIV compounds has become necessary. This aggressive therapy requires at least two nucleoside inhibitors and a protease inhibit or to prevent increases in the serum RNA copy number of the virus. ${ }^{1}$ Therefore, it is necessary to have a continuous development of new antiviral compounds to deter these HIV-resistant mutants.

The purpose of these experiments was to study the new Food and Drug Administration-approved investigational phase 3 drugs, abacavir (a nucleoside inhibitor) and amprenavir (a protease inhibitor) in the ex vivo human placental model for transplacental passage. Both are attractive agents for possible treatment of $\mathrm{HIV}$-infected pregnant women.

Grant sponsor: Glaxo Wellcome.

Correspondence to: Roger E. Bawdon, PhD, Department of Obstetrics and Gynecology, The University of Texas Southwestern Medical Center, 5323 Harry Hines Boulevard, Dallas, TX 75235-9032. 


\section{MATERIALS AND METHODS}

Investigational drugs abacavir hemisulfate [(1S,cis)-4-(2-amino-6-(cyclopropylamino)-9Hpurin-9-y1)-2-cyclopentane-1-methanol sulfate mw 670.7] and amprenavir [(3S)-tetrahydro-3-furylN((1S,2R)-3-(4-amino-N-isobutybenzenesulfamido)1-benzyl-2-hydropropyl)carbonate, mw 505.64] were provided by Glaxo Wellcome (Research Triangle, NC). All chemicals were purchased from Sigma Chemical Company (St. Louis, MO).

All placentas used in this study were obtained from normal term vaginal or cesarean section deliveries. This study was approved by the University of Texas Southwestern Medical Center Institutional Review Board for Human Studies. Placentas were transported to the perfusion laboratory in a bath of normal saline within minutes of separation from the uterus. A suitable nontraumatized cotyledon was identified. The fetal artery and vein were then cannulated with umbilical vessel catheters. The cotyledon was then gently perfused with heparinized drug-free Earles minimal essential medium as previously described. ${ }^{2}$

Each placenta was then perfused with the perfusion media for 15-30 minutes to stabilize the placenta and remove retained blood. ${ }^{14} \mathrm{C}$ antipyrine $(0.1 \mathrm{mg} / \mathrm{mL}$ with a specific activity of 56,600 $\mathrm{dpm} / \mu \mathrm{g}$ ) was used to determine maternal fetal match, transport fraction (TF), and clearance index (CI) of the antiviral drugs. ${ }^{14} \mathrm{C}$ antipyrine was purchased from ICN Biomedical (Irvine, CA). The TF and CI were established using the formula from Challier. ${ }^{3}$ Since antipyrine is a small molecule, a single pass in an open perfusion system results in at least a $40 \%$ maternal-to-fetal transfer. This is an indication of a successful maternal-fetal match. The maternal and fetal circulations were either open-open, respectively, to determine TF and CI or closed-closed to determine accumulation of the drugs. Both the maternal and fetal systems contained $150 \mathrm{~mL}$ of media.

The concentrations of both drugs studied in the perfusion model were the approximate peak and trough concentrations at a proposed maximum single dose of 1,200 mg (Investigational Manual). For abacavir the concentrations were $10 \mu \mathrm{g} / \mathrm{mL}$ and $1 \mu \mathrm{g} / \mathrm{mL}$, and for amprenavir $7 \mu \mathrm{g} / \mathrm{mL}$ and 1.0 $\mu \mathrm{g} / \mathrm{mL}$ peak and trough, respectively. At least six studies were performed at each concentration. In all perfusion studies approximately $2 \mathrm{~mL}$ of perfusate was collected every 5-10 minutes for one hour for drug and $\mathrm{C}^{14}$ antipyrine analysis.

All samples were analyzed by high pressure liquid chromatography (HPLC). The HPLC instrumentation consisted of a 486 UV detector, WISP auto sampler (Waters Associates, Milford, ME), 110 pump (Beckman Instruments, Houston, TX), a 10 $\mathrm{mv}$ recorder (Fisher Scientific), and a $300 \mathrm{~mm} \times 10$ $\mathrm{mm}$ bond-a-clone $10, \mathrm{C}_{18}$ column (Phenomenex, Torrance, CA). The assay for abacavir consisted of extracting the samples with an equal volume of acetonitrile, centrifuged at $3000 \mathrm{~g}$ for 10 minutes, followed by the injection of $20 \mu \mathrm{L}$ of sample into the HPLC. The mobile phase consisted of a buffer consisting of $17 \mathrm{~mL} 85 \%$ phosphoric acid, $30 \mathrm{~mL}$ triethylamine and $945 \mathrm{~mL}$ of water with the $\mathrm{pH}$ adjusted to 7.2 with ammonium hydroxide. Two hundred $\mathrm{mL}$ of this buffer was combined with 800 $\mathrm{mL}$ of methanol. The flow rate of the system was $1.0 \mathrm{~mL} / \mathrm{min}$. The UV detector was set at a wavelength of $284 \mathrm{~nm}$ at a sensitivity setting of $0.01 \mathrm{AU}$. A standard curve that breached the therapeutic range of abacavir was prepared and extracted as with the perfusion sample. The retention time of the drug was about eight minutes. Within-batch and between-batch reproducibility studies were done on previously prepared samples that were analyzed at least in duplicate over three days.

The HPLC method for amprenavir used the same instrument as described above. The sample extraction was also identical. The mobile phase consisted of $430 \mathrm{~mL}$ of acetonitrile and $570 \mathrm{~mL}$ of water which was filtered through a $0.45 \mu$-millpore filter (Millipor Corporation, Melford, MA). The flow rate of the system was $2.0 \mathrm{~mL} / \mathrm{min}$, and the UV detector was set at a wavelength of $270 \mathrm{~nm}$. The sensitivity of the detector was set at $0.005 \mathrm{AU}$. A standard curve that breached the therapeutic range of amprenavir was prepared and extracted with the perfusate sample. Twenty microliters were injected into the system, and the retention time of the drug was about seven min. Withinbatch and between-batch reproducibility studies were done on samples prepared as described previously for abacavir.

\section{RESULTS}

The within-batch and between-batch recovery studies for both abacavir and amprenavir were 
TABLE I. Clearance index of abacavir and amprenavir

\begin{tabular}{lccc}
\hline Drug & Concentration & $\mathrm{Cl} \pm \mathrm{SD}$ & $\begin{array}{c}\text { Accumulation } \\
\pm \mathrm{SD}\end{array}$ \\
\hline Abacavir $^{\mathrm{a}}$ & $1.0 \mu \mathrm{g} / \mathrm{mL}$ & $0.47 \pm 0.19$ & $0.67 \pm 0.10$ \\
Abacavir $^{\mathrm{a}}$ & $10.0 \mu \mathrm{g} / \mathrm{mL}$ & $0.50 \pm 0.07$ & $2.47 \pm 0.79$ \\
Amprenavir $^{b}$ & $1.3 \mu \mathrm{g} / \mathrm{mL}$ & $0.14 \pm 0.08$ & $0.06 \pm 0.06$ \\
Amprenavir $^{\mathrm{a}}$ & $6.7 \mu \mathrm{g} / \mathrm{mL}$ & $0.38 \pm 0.09$ & $0.67 \pm 0.51$ \\
\hline${ }^{\mathrm{a}} \mathrm{n}=6$ & & & \\
${ }^{b} \mathrm{n}=8$ & & & \\
SD $=$ standard deviation. & &
\end{tabular}

$>80 \%$, and the minimum sensitivity was $\leq 0.1$ $\mu \mathrm{g} / \mathrm{mL}$ (data not shown). The CI and accumulation after one hour for both abacavir and amprenavir are depicted in Table 1.

Placental tissue samples at $1.0 \mu \mathrm{g} / \mathrm{mL}$ of abacavir were not done. The placental tissue concentration of abacavir at the therapeutic peak (10 $\mu \mathrm{g} / \mathrm{mL}$ ) was $2.38 \pm 1.25 \mu \mathrm{g} / \mathrm{g}$ at $10 \mu \mathrm{g} / \mathrm{mL}$. The placental tissue concentrations of amprenavir were $0.06 \pm 0.06 \mu \mathrm{g} / \mathrm{g}$ and $0.67 \pm 0.51 \mu \mathrm{g} / \mathrm{g}$ at trough and peak concentrations, respectively.

\section{DISCUSSION}

Abacavir is the first nucleoside inhibitor studied with a high CI of about $50 \%$ that of antipyrine. Other nucleoside inhibitors have been shown to have a CI of 0.14 to 0.29 in our and other laboratories. ${ }^{2,4,5}$ This suggests that abacavir is highly lipophilic and is readily transferred across the human placenta by simple diffusion., ${ }^{2,4-6}$ Because the drug readily crosses the placenta, abacavir could be clinically useful in the treatment of HIV-1 in the pregnant patient and prevention of perinatal HIV transmission.

Amprenavir crosses the placenta more readily than ritonavir in the ex vivo placental model. ${ }^{2,6,7}$ At trough concentrations, ritonavir was not detectable in the fetal compartment and at peak concentration, amprenavir had a low CI, but it was approximately 2.75 times that of ritonavir. ${ }^{7}$ These data are supported by the placental transfer of protease inhibitors in rabbit studies. ${ }^{1}$

Although there is a larger difference in the CI of these compounds compared with other anti-HIV drugs studied, the clinical significance of these differences remains unclear. Regardless of these differences it is important to note because these drugs readily cross the placenta; treatment of the pregnant patient results in exposure to the fetus. Although there is a paucity of information on the use of triple therapy in the pregnant patient, it is important that new nucleoside and protease inhibitors are available for treatment in these patients. Since there is a possibility that the use of three or more drug combinations may completely suppress viral replication, the inclusion of combination therapy in the pregnant patient is of utmost importance. However, the short-term and long-term impact of this aggressive therapy on the fetus and infant is unknown.

There is also insufficient data to support or refute teratogenic risk of triple antiviral therapy in the first trimester of pregnancy. In any case, zidovudine should be included in any regimen, since it is the only drug that has been shown to reduce perinatal transmission. Regardless of the therapy initiated, informed consent of the patient is important, and perinatal exposure to anti-HIV therapy should be reported to the Antiretroviral Pregnancy Register, 800-258-4263. ${ }^{1}$

\section{REFERENCES}

1. Centers for Disease Control and Prevention: MMWR Morb Mortal Wkly Rep 47(RR-5):43-82, 1998.

2. Bawdon RE, Kaul S, Sobhi S: The ex vivo human placental transfer of the anti-HIV nucleoside compound d4T. Gynecol Obstet Invest 38:1-4, 1994.

3. Challier JC: Criteria for evaluating perfusion experiments and presentation of results. Contrib Gynecol Obstet 13:32-39, 1985.

4. Liebes L, Mendoza S, Wilson D, Dancis J: Transfer of zidovudine (AZT) by human placenta. J Infect Dis 161: 203-207, 1990.

5. Schenker S, Johnson RF, King TS, Schenken RS, Henderson GI: Azidothymidine (zidovudine) transport by the human placenta. Am J Med Sci 229:16-20, 1990.

6. Bawdon RE: Ex vivo human placental transfer of antiHIV compounds. J Infect Dis Obstet Gynecol 5:310315, 1997.

7. Casey BM, Bawdon RE: Placental transfer of ritonavir with zidovudine in the ex vivo placental perfusion model. Am J Obstet Gynecol 179:758-761, 1998. 


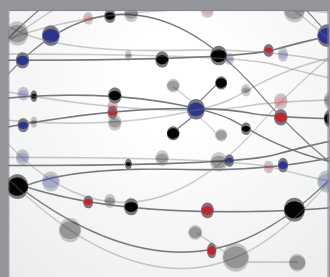

The Scientific World Journal
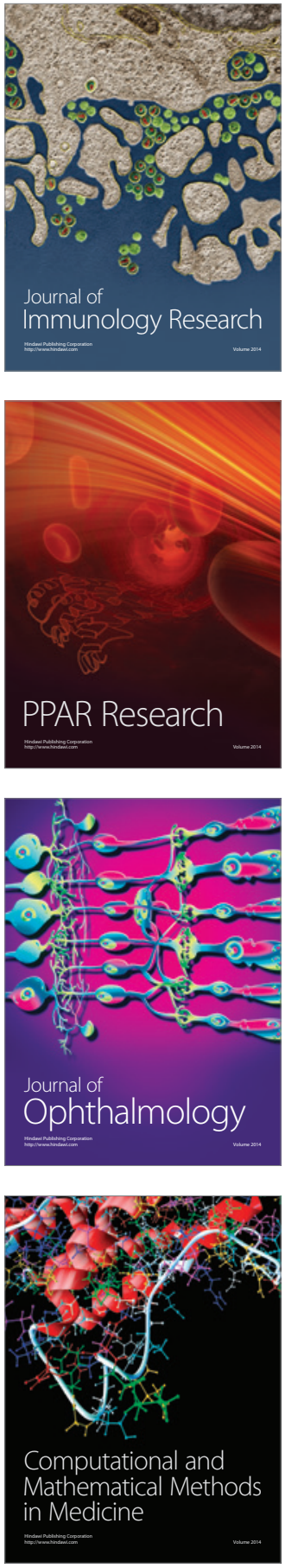

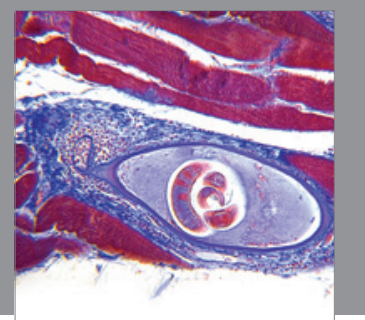

Gastroenterology

Research and Practice
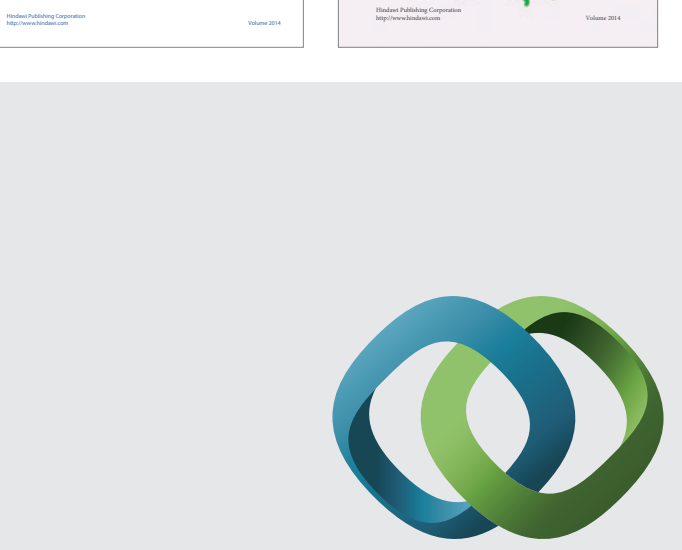

\section{Hindawi}

Submit your manuscripts at

http://www.hindawi.com
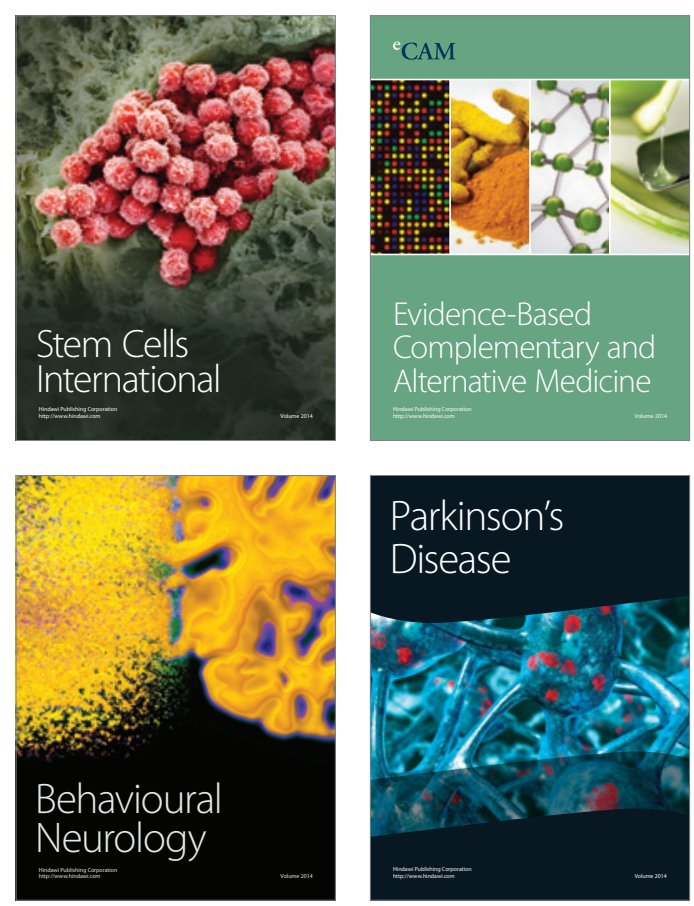

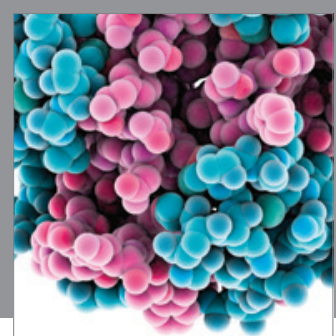

Journal of
Diabetes Research

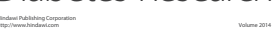

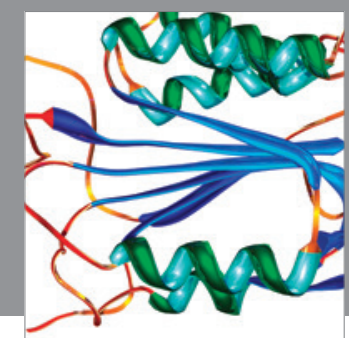

Disease Markers
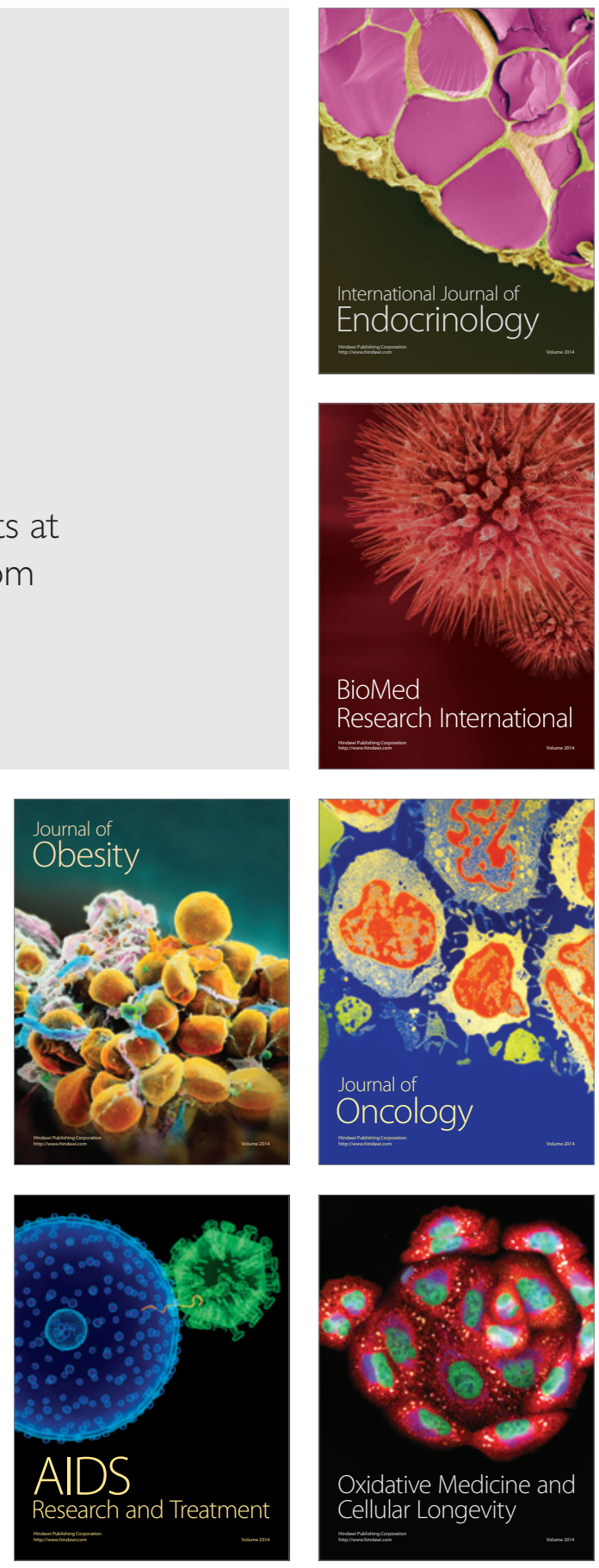